Gut, 1971, 12, 625-628

\title{
Alimentary transit and supersensitivity after vagotomy in the rat
}

\author{
L. V. GUTIERREZ ${ }^{1}$, N. KOCAK ${ }^{2}$, AND ALAN G. COX \\ From the Department of Surgery, Royal Postgraduate Medical School, London
}

SUMmaRY The effect of a subthreshold dose of carbachol on alimentary transit of a radioisotopically labelled fluid test meal was measured before and after vagotomy and pyloromyotomy in rats. Vagotomy itself had a transient slowing effect on the rates of gastric emptying and transit in the upper small intestine. Subthreshold carbachol had no effect before vagotomy but accelerated gastric emptying and small intestinal transit after vagotomy. These findings might explain the increased bowel frequency which is common after vagotomy.

Disturbances of alimentary movements are well recognized side-effects of surgical vagotomy, and many patients note increased bowel frequency after vagotomy (Cox and Bond, 1964). There is also good evidence of an altered pattern of gastric emptying (Goodall, 1966; Griffith, Owen, and Shields, 1966; Buckler, 1967; McKelvey, 1970). These phenomena have been investigated fairly intensively but agreement is still lacking on their precise characteristics. One possible reason for this is that relatively little has been done to examine the physiological basis of any changes that do occur. For example, there is very little information on the motor response of the denervated alimentary tract to external stimuli such as parasympathomimetic agents.

The purpose of the present study was to investigate the effect of vagotomy on transit through the stomach and small intestine and, in particular, to identify the effect of subthreshold doses of carbachol on the denervated stomach and gut. Our interest in the response to subthreshold carbachol arose out of our previous observations that the gallbladder after vagotomy contracts under the influence of a dose of carbachol too small to cause contraction of the normal gallbladder (Tinker and Cox, 1969). This type of response is consistent with the law of supersensitivity proposed by Cannon (1939).

${ }^{1}$ Present address: Dep. Cirurgia, Hosp. C. Argerich, A. Brown 240, Buenos Aires, Argentina

'Present address: Sisli Siracevizler, Gunayoi-1 Apt 81, Kat 4 Daire 12, Istanbul-Sisli, Turkey

'Present address: Clinical Research Centre, Northwick Park Hospital, Watford Road, Harrow, Middlesex

Received for publication 20 May 1971.

\section{Materials and Methods}

\section{ANIMALS}

Four groups of 60 adult Wistar rats weighing about $250 \mathrm{~g}$ were studied. These groups were studied as follows: (1) no operation done-_control'; (2) a pyloromyotomy was done under general anaesthesia eight days previously_-pyloromyotomy'; (3) truncal vagotomy and pyloromyotomy were done under general anaesthesia eight days previously-'early vagotomy'; (4) truncal vagotomy and pyloromyotomy were done under general anaesthesia 30 days previously_'late vagotomy'.

In each group of 60 rats, 30 received a subthreshold dose of carbachol and 30 received normal saline, each given subcutaneously in the back. The subthreshold dose of carbachol was found to be 0.02 $\mu \mathrm{g} / \mathrm{kg}$ in a pilot study of changes in intragastric pressure in response to different doses of carbachol. The suitability of this dose was confirmed by the results of the present study.

\section{MEASUREMENT OF GASTRIC AND INTESTINAL} TRANSIT

The method used was a modification of that described by Nylander and Wikström (1967 and 1968). A radioisotopically labelled test meal was deposited in the stomach and the amount in different parts of the gastrointestinal tract was measured at fixed time intervals. The meal contained glucose $(1 \mathrm{mg})$, phenol red $(1 \mathrm{mg})$, polyethylene glycol $(5 \%)$, phosphate buffer $(1 \mathrm{ml}, p \mathrm{H} 7 \cdot 2)$, and $10 \mathrm{mCi}$ of radioactive chromate $\mathrm{Cr}^{51} \mathrm{O}_{4} \mathrm{Na}_{2}$. The chromate portion is not 
absorbed and is biologically inert. The procedure in each rat was as follows: the rat was anaesthetized lightly with Penthrane and an orogastric tube positioned with its tip in the stomach. The meal was instilled gently into the stomach and the rat was then given an injection of either saline or carbachol. The tube was removed and the rat regained consciousness immediately. Equal numbers of rats in each group were killed 10, 20, and 40 minutes later. The alimentary tract was removed at once and divided into the following parts: stomach, small intestine in four equal parts, and colon. Each segment was placed in $5 \mathrm{ml}$ of acetic acid and the amount of radioactivity measured in a gamma counter 48 hours later.

Transit through the stomach and each segment of the small intestine were calculated in the same way according to the following formula:

$$
\text { transit }=\frac{A}{A+B} \times 100
$$

where $\mathbf{A}=$ amount of radioactivity distal to the part of alimentary tract under consideration and $\mathrm{B}=$ amount of radioactivity in the part of alimentary tract under consideration.

In order to conform with the usual nomenclature, the terms used will be gastric emptying (for the stomach) and transit (for the small intestine).

\section{STATISTICAL ANALYSIS}

Student's t test was used to analyse the statistical significance of difference between means, and $P$ values less than 0.01 were regarded as significant. This rather strict criterion was applied because the large number of analyses done would be expected to give rise to 'significant' values at a less stringent level of significance.

\section{Results}

The results are presented in two parts. First, a comparison is made between the normal controls and the animals subjected to various operations. Second, the effect of subthreshold carbachol is examined ${ }^{1}$.

\section{EFFECT OF OPERATIONS (FIG. 1)}

The rate of gastric emptying was unaffected by pyloromyotomy alone. Eight days after vagotomy

${ }^{1}$ In this paper, the data are illustrated diagrammatically because the tables are extensive and rather indigestible. The tabulated dat a will be sent to anyone who requests them from A. G. Cox.

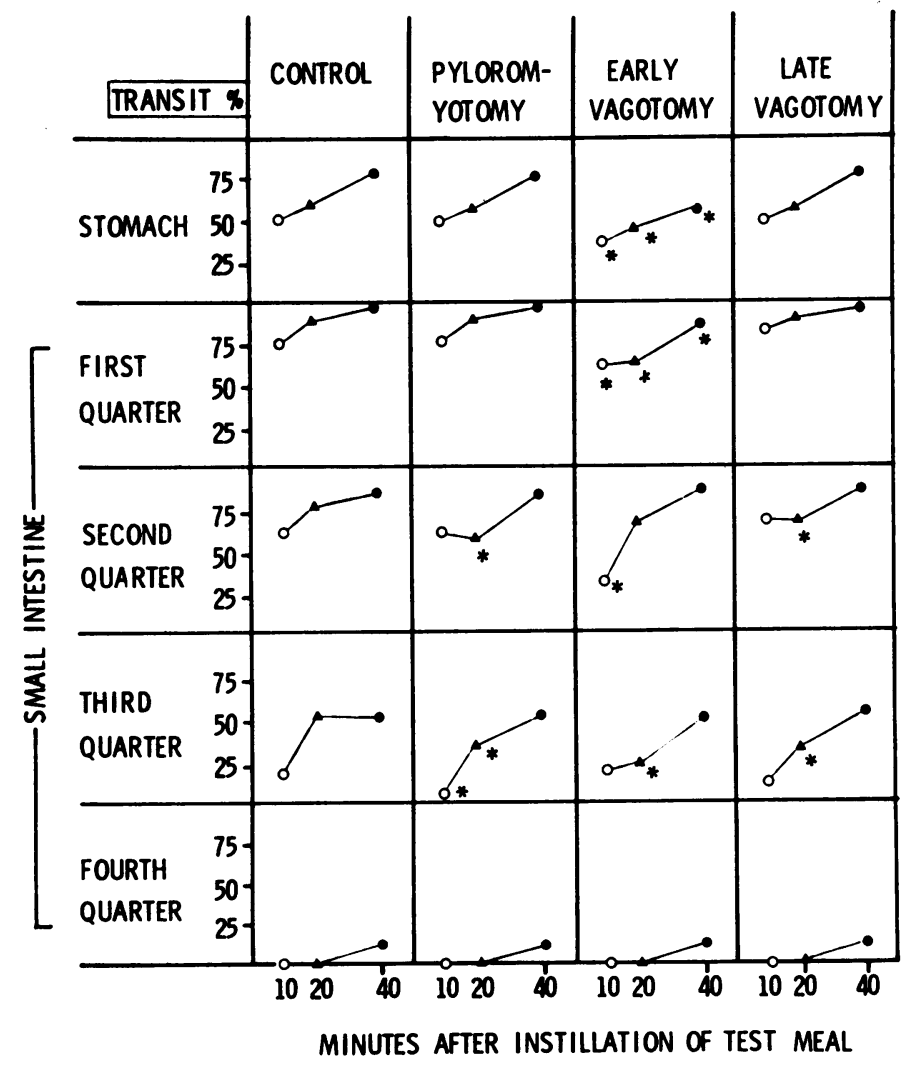

Fig. 1 Gastric and small intestinal transit in four groups of rats: (1) normal controls, (2) eight days after pyloromyotomy, (3) eight days after truncal vagotomy with pyloromyotomy ('early vagotomy'), and (4) 30 days after truncal vagotomy with pyloromyotomy ('late vagotomy'). Each point represents the mean of experiments in 30 rats. The points marked with an asterisk represent means significantly lower than the corresponding means in the controls $(\mathrm{P}<0.01)$. 


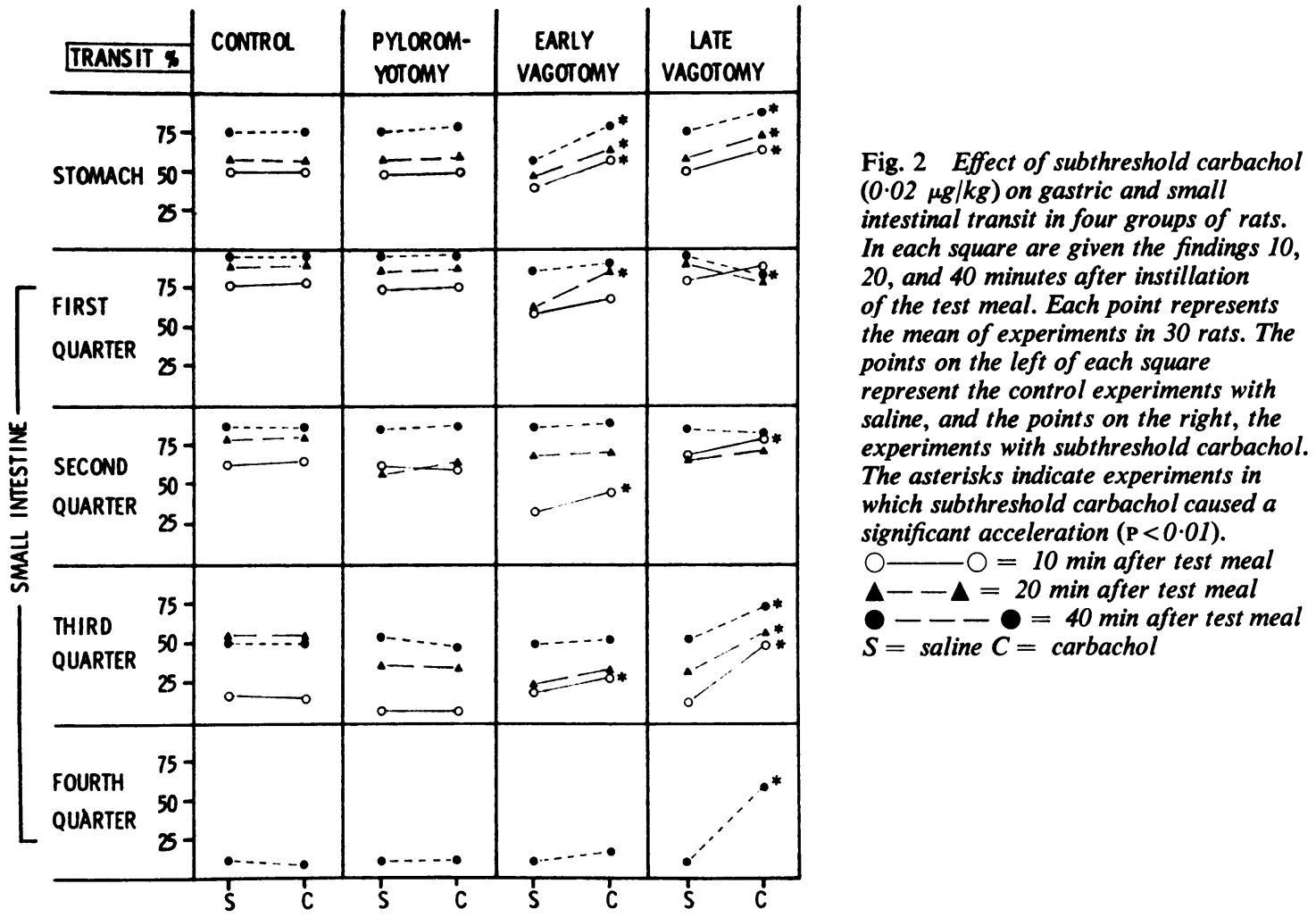

with pyloromyotomy it was significantly reduced but had returned to a nearly normal rate 30 days after vagotomy with pyloromyotomy.

Intestinal transit was decreased at various levels of the small intestine after all three operations. However, the pattern was somewhat inconsistent and the only really convincing change was seen early after vagotomy when there was a uniformly reduced transit rate in the first segment of the small intestine. All the other changes after vagotomy, both early and late, could be matched with similar findings after pyloromyotomy alone and might therefore be attributed to pyloromyotomy or a nonspecific effect of operation.

\section{EFFECT OF SUBTHRESHOLD CARBACHOL} (FIG. 2)

In both the control rats and those after pyloromyotomy, the dose of carbachol had no effect on gastric emptying and intestinal transit. This confirms that the dose of carbachol was subthreshold, as intended.

After vagotomy, both early and late, subthreshold carbachol caused a statistically significant and uni- form acceleration of gastric emptying. In the small intestine, there were similar changes; out of the 20 comparisons made, 17 showed an increased transit, and nine of these were statistically significant with $P$ value below 0.01 .

\section{Discussion}

Our finding that gastric emptying is delayed soon after vagotomy but returns to essentially normal levels at a later interval is in accord with clinical observation and our own measurements in man (unpublished data). The effect of vagotomy on transit in the small intestine was far less clear cut. Our results suggested that the uppermost segment of the small intestine behaved in the same way as the stomach but that the remainder was little affected. This difference between the upper and lower small intestine might be due to differences in the balance between excitatory (vagal) and inhibitory (splanchnic) nerves to the small intestine. Kewenter (1965) found that the vagal excitatory fibres are distributed more or less equally to jejunum and ileum, whereas the splanchnic inhibitory fibres go mainly to the 
ileum, and suppress completely the vagal excitatory function at that level. Therefore vagal dene.vation of the jejunum would deprive that area of a functionally active and excitatory stimulus, leading to delayed transit. In contrast, vagal denervation of the ileum would not be expected to lead to significant motility changes because vagal function at that level is masked by the function of the splanchnics. Our results showed a return to normal in the small intestine $\mathbf{3 0}$ days after vagotomy. This may reflect the relative unimportance of the extrinsic innervation of the small intestine and point to the capacity of the intrinsic innervation to restore normal function.

The finding that subthreshold doses of carbachol accelerated gastric emptying confirmed our previous findings in man and dog (Tinker, Kocak, Jones, Glass, and Cox, 1970) and was consistent with Cannon's law of supersensitivity. In the small intestine, similar changes were observed but were less consistent. The effect of carbachol was slight in the jejunum; this might be due to the rapid transit at that level which would tend to obscure acceleration. In the ileum, accelerated transit was more obvious (Fig. 2). This might be due to the relatively slow transit at this level but this seems inconsistent with the view that the vagus is functionally unimportant in the ileum. However, the concept of supersensitivity applies to the end organ-in this case, intestinal smooth muscle-and our findings suggest that the inhibitory effect of the splanchnics is insufficient to mask supersensitivity.

The clinical relevance of these findings remains a matter for speculation. The most interesting possibility is that supersensitivity is responsible for the increase in daily bowel frequency which occurs in some $70 \%$ of patients after vagotomy (Cox and Bond, 1964). This could be explained on the basis of subihreshold levels of circulating excitatory agents, eg, serotonin, which would have no clinically noticeable effect before vagotomy. In a previous study, we found that the phenomenon of supersensitivity after vagotomy could be elicited by a hormone as well as by a parasympathomimetic drug (Tinker and Cox, 1969). This theory would provide a physiological basis for the observation (Kennedy and Connell, 197 ? that the incidence of diarrhoea is less when the vagotumy is done in a way to prevent denervation of the small intestine ('selective vagotomy'). However, it is difficult to see how supersensitivity could explain the attacks of explosive diarrhoea which afflict some pa.ents at regular intervals after vagotomy.

\section{References}

Buckler, K. G. (1967). Effects of gastric surgery upon gastric emptying in cases of peptic ulceration Giul, \&, 137-147.

Cannon, W. B. (1939). A law of denervation. Amer. J. med. Sci., 198, 737-750.

Cox, A. G., and Bond, M. R. (196-). Bou el hahit after vagotomy and gastrojejunostomy. Brit. med. J., J. 460465.

Goodall, P. (1966). The effect of vagotom: and a Jrainage procedure on the rate of gastric emptying. Brit. '. Surg . 5.3, 995 .

Griffith, G. H., Owen, G. M., and Shields, R. (1966). rie rate of gastric emptying in gastroduodenal disease. Brit I Surk, 53, 995.

Kennedy, T., and Connell, A. M. (1970). Selective or Iruncal vagotomy ? Lance , 1, 675.

Kewenter, J. (1965): The vagal control of the jejunal and iteal motility and blood flow. Acta physiol. scand., 65, Suppl. 251

McKelvey, S. T. D. (1970). Gastric incontinence and post vagivomy diarrhoea. Brit. J. Surg., 57, 741-747.

Nylander, G., and Wikström, S. (1967). Gastric emptyıng and p"opulsive intestinal motility following partial gastr1: :e-ect101, Gastroenteroanastomosis and abdominal 'trunk' vagorom. in the rat. Acta chir. Scand, 133, 41-54.

Nylander, G., and Wikström, S. (1968). Propulsive gastroincestına। motility. Acta ch r. scand., Suppl. 385, 36-51.

Tinker, J., and Cox. A. G. (1969). Gall bladder function after v. go tomy. Brit. J. Surg., 56, 779.782.

Tinker, J., Kocak, N., Jon':, T., Glass, H. I., and Cox, A. G. (1970:Supersensitivity and gastric emptying after vagotomy. Gut 11, 502-505. 